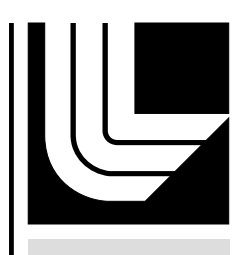

LAWRENCE LIVERMORE N A TION A L LABORATORY

Soft X-ray Studies of Pu Electronic Structure: Past Lessons and Future Directions

J. G. Tobin, S. W. Yu

February 11, 2008

Symposium Proceedings of the Materials Research Society 
This document was prepared as an account of work sponsored by an agency of the United States government. Neither the United States government nor Lawrence Livermore National Security, LLC, nor any of their employees makes any warranty, expressed or implied, or assumes any legal liability or responsibility for the accuracy, completeness, or usefulness of any information, apparatus, product, or process disclosed, or represents that its use would not infringe privately owned rights. Reference herein to any specific commercial product, process, or service by trade name, trademark, manufacturer, or otherwise does not necessarily constitute or imply its endorsement, recommendation, or favoring by the United States government or Lawrence Livermore National Security, LLC. The views and opinions of authors expressed herein do not necessarily state or reflect those of the United States government or Lawrence Livermore National Security, LLC, and shall not be used for advertising or product endorsement purposes. 
Spring 2008 Materials Research Society Meeting

Actinides IV, Symposium NN

San Francisco, CA, USA

March 24-28, 2008

\section{Soft X-ray Studies of Pu Electronic Structure: Past Lessons and Future Directions}

\section{J.G. Tobin and S.W. Yu}

\section{Lawrence Livermore National Laboratory, LLNS-LLC, Livermore, CA, USA}

Photoelectron Spectroscopy (PES) [1] and X-ray Absorption Spectroscopy (XAS, Figure 1) [2-4] have contributed greatly to our improved understanding of $\mathrm{Pu}$ electronic structure. From these and related measurements, the following has been determined.

1. The Pu $5 f$ spin-orbit splitting is large.

2. The number of Pu5f electrons is near 5 .

3. The Pu $5 f$ spin-orbit splitting effect dominates $5 f$ itineracy.
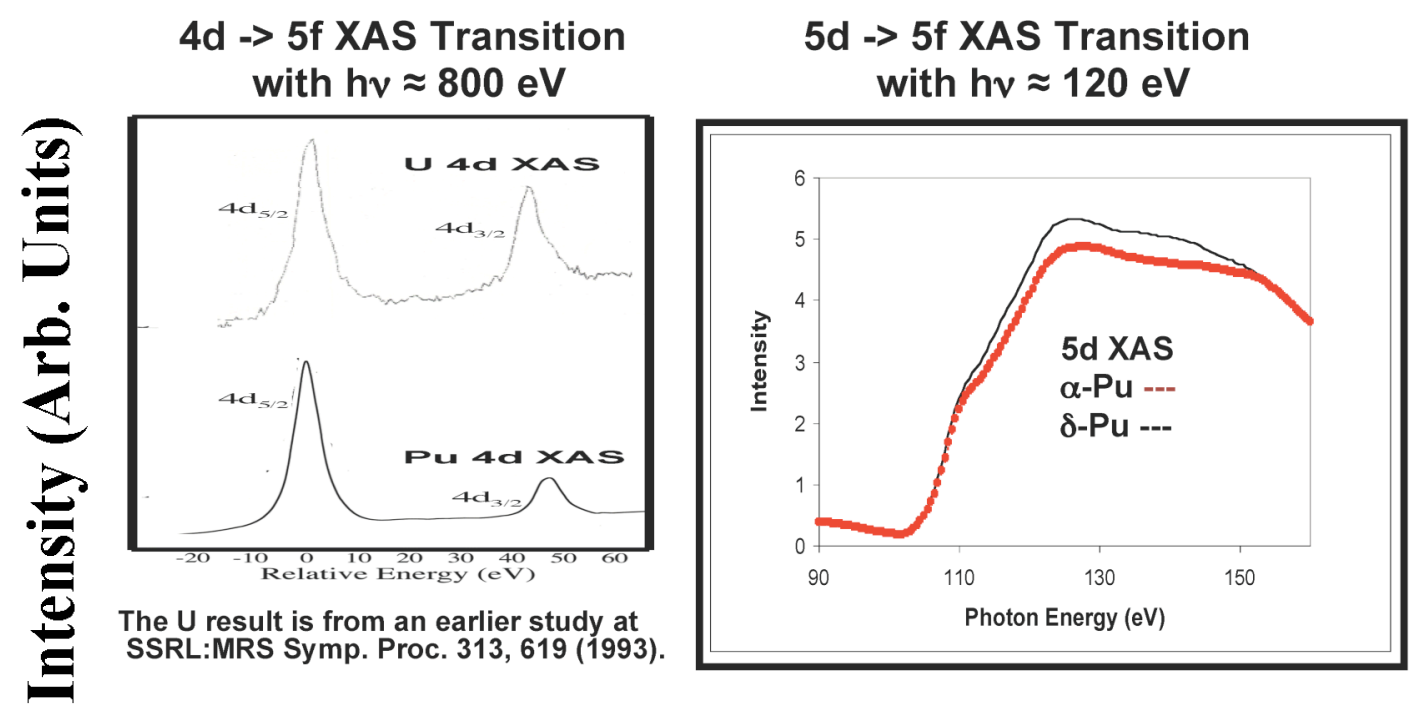

Figure 1

Significant questions remain concerning the nature of Pu electronic structure. Perhaps the missing piece of the puzzle is the direct experimental determination of the unoccupied electronic structure using high energy inverse photoelectron spectroscopy or Bremstrahlung Isochromat Spectroscopy (BIS). [5] Past BIS studies of Th and $U$ indicate the feasibility and utility of Pu studies. [6] 
Spring 2008 Materials Research Society Meeting Actinides IV, Symposium NN

San Francisco, CA, USA

March 24-28, 2008

To this end, a new BIS capability has been developed in our laboratory, as shown schematically in Figure 2 below. [7]

\section{LLNL Fano and BIS Spectrometer}

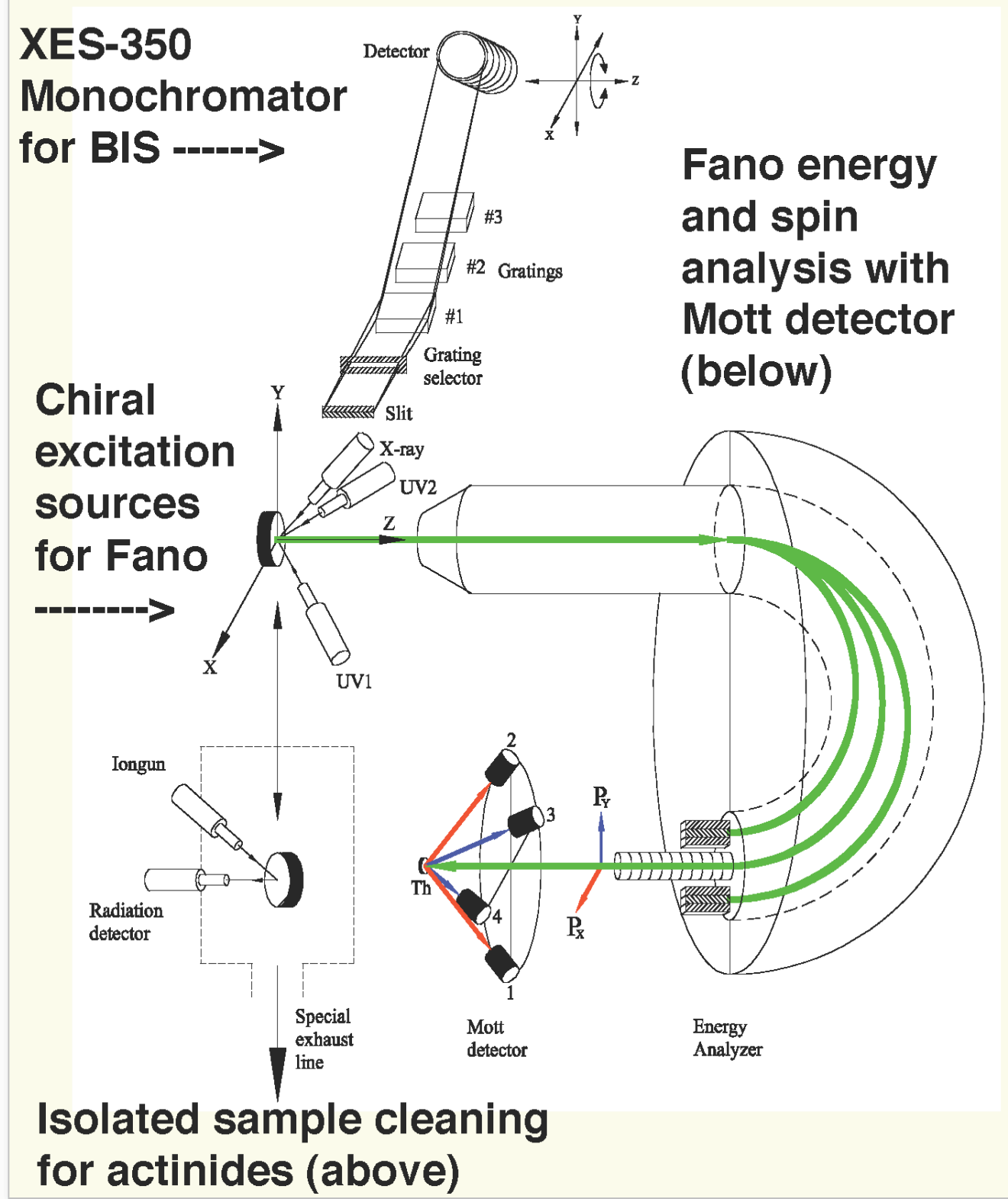

Figure 2 
Spring 2008 Materials Research Society Meeting

Actinides IV, Symposium NN

San Francisco, CA, USA

March 24-28, 2008

Electron stimulated emission of photons has been carried out using the XES-350 monochromator and detector system. Some of our preliminary results are shown below, using an electron excitation beam energy of $3000 \mathrm{eV}$.

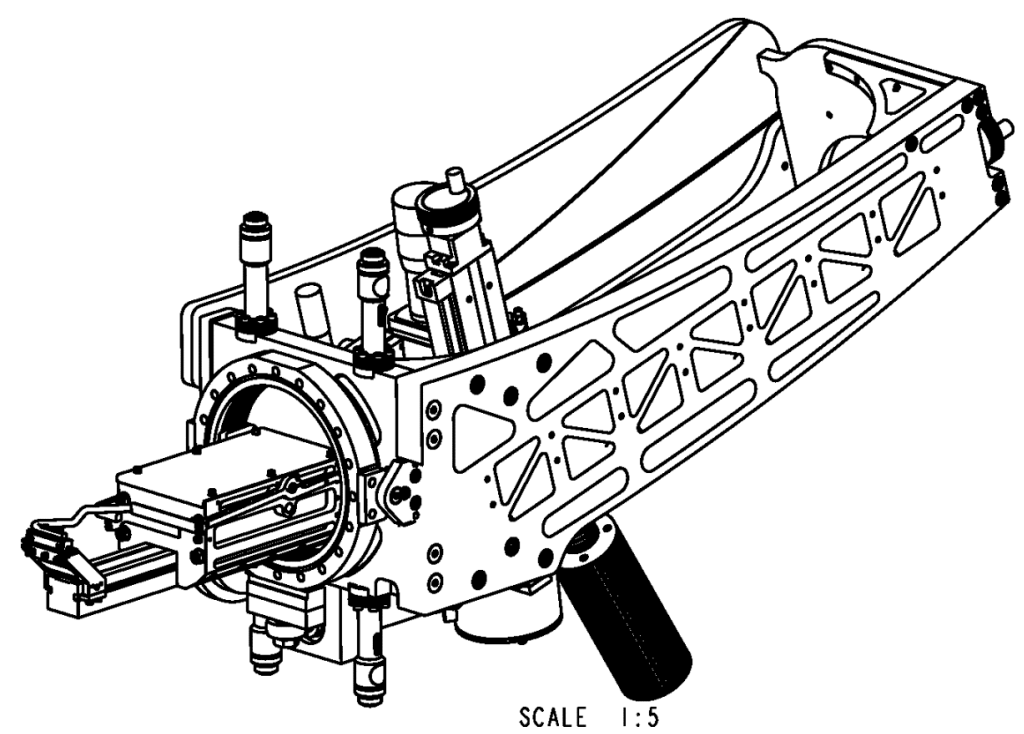

Figure 3

XES-350 A Schematic of the monochromator and detector is shown here. Figure provided by Scienta.

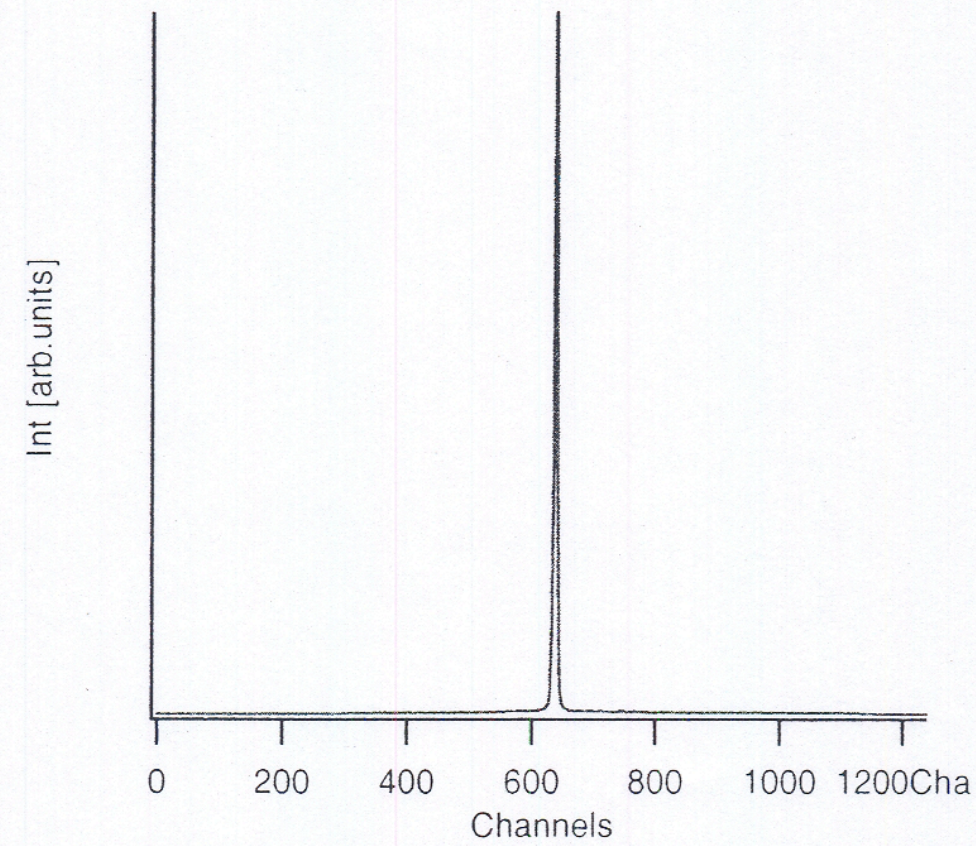

The $0^{\text {th }}$ order peak with a $10 \mu \mathrm{m}$ slit at the focus position. The FWHM is $\sim 5$ channels.

Figure 4

Tobin

Page 3 
Spring 2008 Materials Research Society Meeting Actinides IV, Symposium NN

San Francisco, CA, USA

March 24-28, 2008

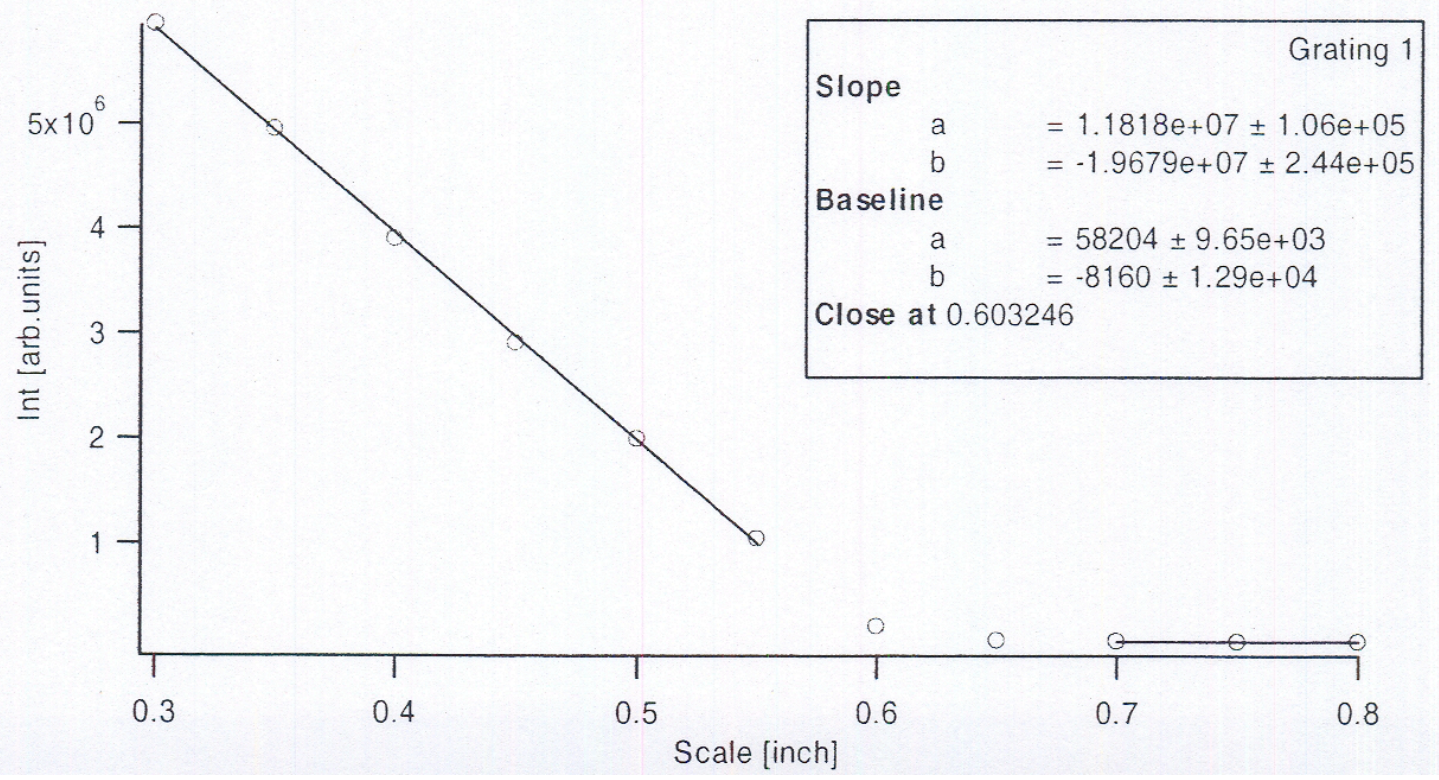

Figure 5

The intensity of the transmitted radiation as a function of the slit inch scale for Grating 1.
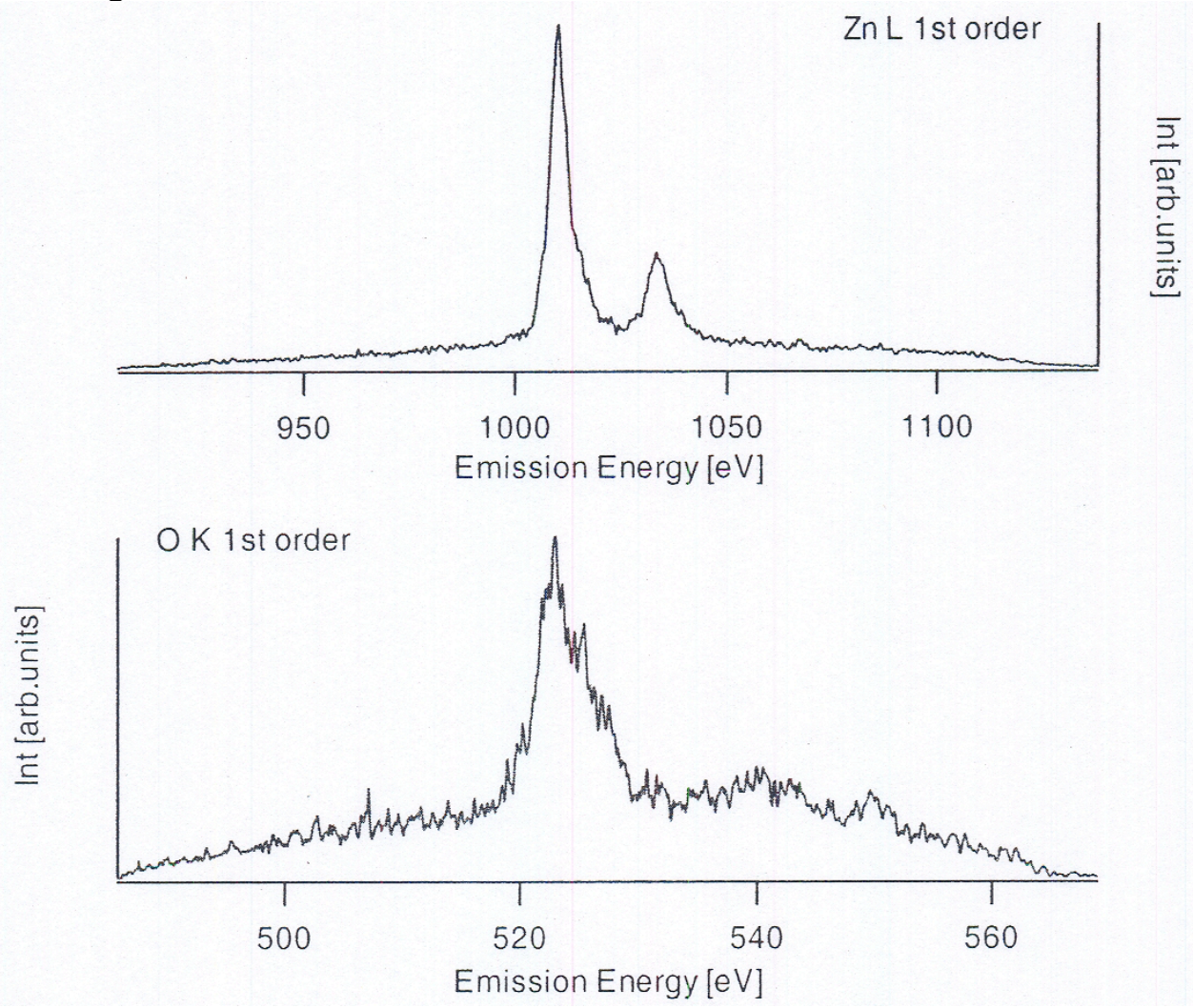

Figure 6

$\mathrm{Zn} \mathrm{L} \mathrm{(2p)} \mathrm{and} \mathrm{O} \mathrm{K} \mathrm{(1s)} \mathrm{emission} \mathrm{in} \mathrm{first} \mathrm{order,} \mathrm{measured} \mathrm{at} \mathrm{the} \mathrm{calculated}$ positions on Grating 1. 
Spring 2008 Materials Research Society Meeting Actinides IV, Symposium NN

San Francisco, CA, USA

March 24-28, 2008

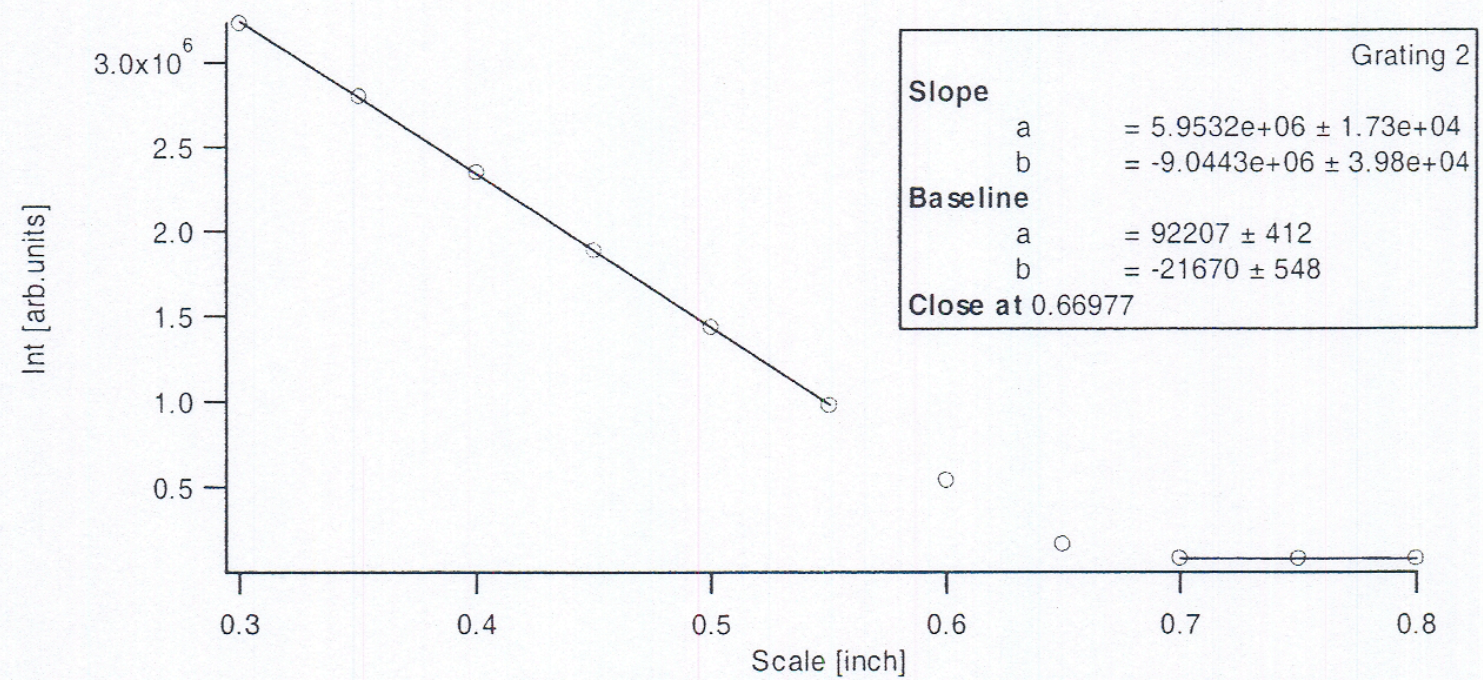

Figure 7

The intensity of the transmitted radiation as a function of the slit inch scale for Grating 2.
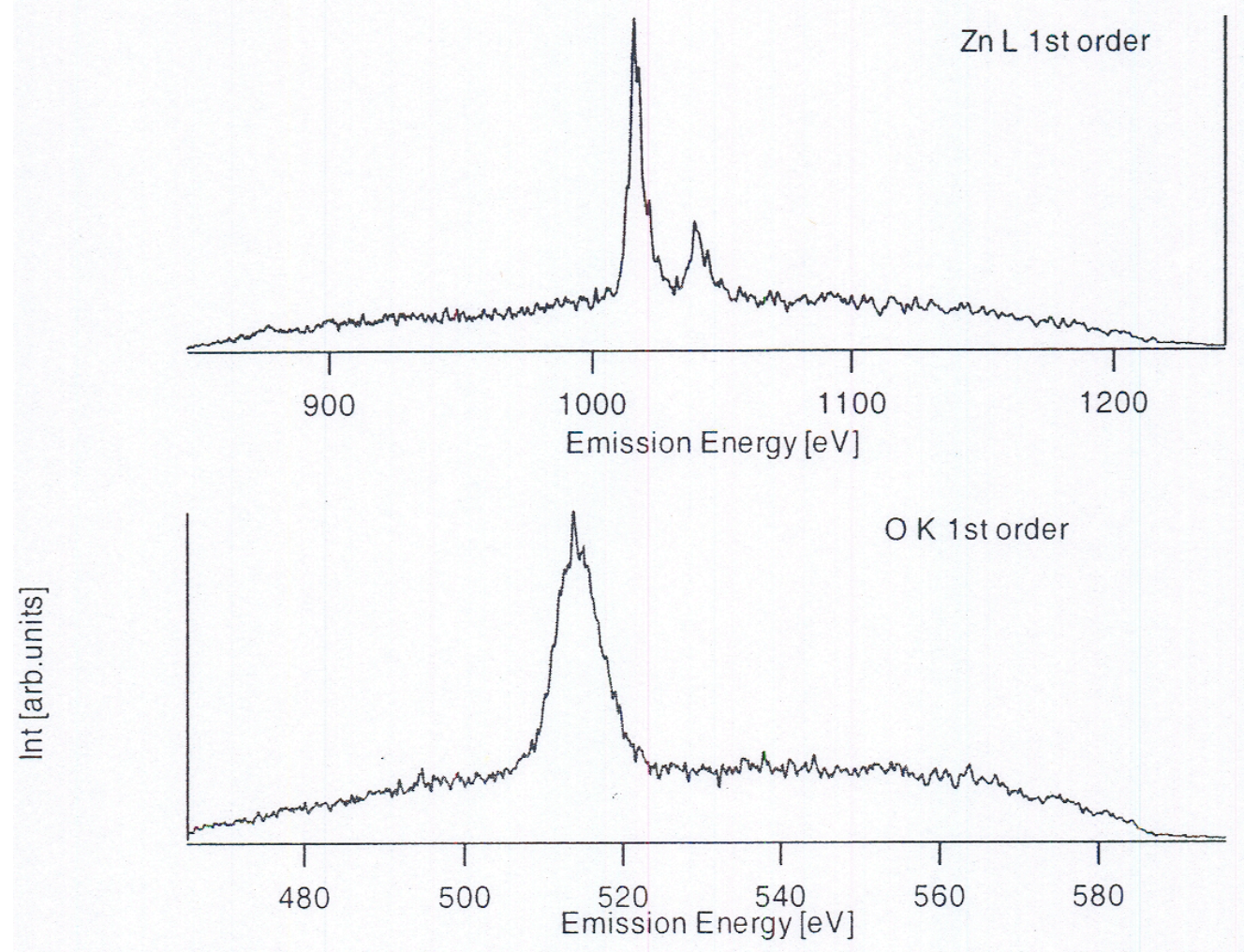

Figure 8

$\mathrm{Zn} \mathrm{L} \mathrm{(2p)} \mathrm{and} \mathrm{O} \mathrm{K} \mathrm{(1s)} \mathrm{emission} \mathrm{in} \mathrm{first} \mathrm{order,} \mathrm{measured} \mathrm{at} \mathrm{the} \mathrm{calculated}$ positions on Grating 2. 
Spring 2008 Materials Research Society Meeting Actinides IV, Symposium NN

San Francisco, CA, USA

March 24-28, 2008

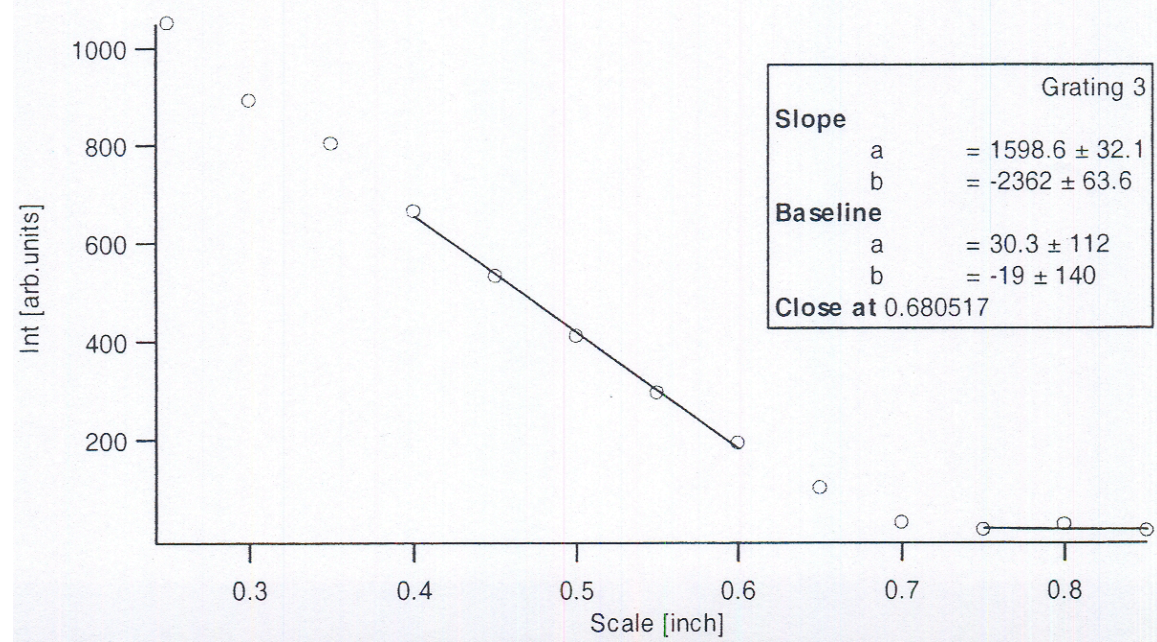

Figure 9

The intensity of the transmitted radiation as a function of the slit inch scale for Grating 3.

Acknowledgements:

Lawrence Livermore National Laboratory is operated by Lawrence Livermore National Security, LLC, for the U.S. Department of Energy, National Nuclear Security Administration under Contract DE-AC52-07NA27344. Work that was performed by LLNL personnel was supported in part by the Office of Basic Energy Science at the U.S Department of Energy and Campaign 2 of $\mathrm{WCI}$ at LLNL. The X-ray emission data was collected at LLNL in collaboration with Gammadata Scienta personnel and M.T. Butterfield. Figures 4 - 9 and the corresponding captions were taken from "SAT XES 350," a technical report from VG Scienta in 2006, provided under contract to LLNL and prepared by Marcus Agaker and Henrik Ohman.

\section{References}

1. J.G. Tobin et al, Phys. Rev. B 68, 155109 (2003).

2. K.T. Moore et al, Phys. Rev. Lett. 90, 196404 (2003).

3. G. van der Laan et al, Phys. Rev. Lett. 93, 097401 (2004).

4. J.G. Tobin et al, Phys. Rev. B 72, 085109 (2005).

5. J.G. Tobin, M.T. Butterfield, N.E. Teslich Jr., R.A. Bliss, M.A. Wall, A.K. McMahan, B.W. Chung and A.J. Schwartz, "Using Nano-focussed Bremstrahlung Isochromat Spectroscopy (nBIS) to Determine the Unoccupied Electronic Structure of Pu," in "Recent Advances in Actinide Science," Royal Society of Chemistry, ed. R. Alvarez, N.D. Bryan and I. May, page 773 (2006).

6. Y. Baer and J.K. Lang, Phys. Rev B 21, 2060 (1980).

7. J.G. Tobin, S.W. Yu, T. Komesu, B.W. Chung, S.A. Morton and G.D. Waddill. MRS Symp. Proc. 986, 63 (2007), Document \# 0986-O001-08. 